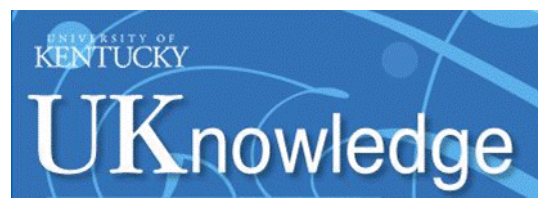

University of Kentucky

UKnowledge

$1-2003$

\title{
Educating Adolescents about Puberty: What are we Missing?
}

Hatim A. Omar

University of Kentucky, hatim.omar@uky.edu

Darby H. McElderry

University of Kentucky

Rana M. Zakharia

University of Kentucky

Follow this and additional works at: https://uknowledge.uky.edu/pediatrics_facpub

Part of the Pediatrics Commons

Right click to open a feedback form in a new tab to let us know how this document benefits you.

\section{Repository Citation}

Omar, Hatim A.; McElderry, Darby H.; and Zakharia, Rana M., "Educating Adolescents about Puberty: What are we Missing?" (2003). Pediatrics Faculty Publications. 83.

https://uknowledge.uky.edu/pediatrics_facpub/83

This Article is brought to you for free and open access by the Pediatrics at UKnowledge. It has been accepted for inclusion in Pediatrics Faculty Publications by an authorized administrator of UKnowledge. For more information, please contact UKnowledge@lsv.uky.edu. 


\section{Educating Adolescents about Puberty: What are we Missing?}

\section{Digital Object Identifier (DOI)}

https://doi.org/10.1515/IJAMH.2003.15.1.79

\section{Notes/Citation Information}

Published in International Journal of Adolescent Medicine and Health, v. 15, no. 1, p. 79-83.

(C) Freund Publishing House Ltd.

The copyright holder has granted permission for posting the article here.

Reprinted as a book chapter in Rural Child Health: International Aspects. Erica Bell, \& Joav Merrick, (Eds.). p. 151-156. 


\title{
Educating Adolescents About Puberty: What Are We Missing?
}

\author{
Hatim Omar, MD, Darby McElderry, MD and Rana Zakharia \\ Section of Adolescent Medicine, Department of Pediatrics, University of Kentucky,
Lexington, KY, USA
}

Abstract: Adolescents undergo significant physical and cognitive changes during their pubertal development. These changes contribute to and impact their future development. Educating adolescents at an early age about their expected development decreases the possible anxiety associated with this period of life and also helps adolescents make better choices in regards to their sexuality. In order to assess the degree of education regarding pubertal development and sexuality, we conducted a survey of late adolescents (Median age 19 years) and parents of adolescents. A total of 409 adolescents (237 females, 172 males) and 124 parents completed the survey. $14.4 \%$ of teens ( $36.6 \%$ of males and $2 \%$ of females) reported that no one spoke to them prior or during puberty about pubertal development or sexuality issues. Teens receiving some form of puberty/sexuality education did so at a median age of 13 for girls and 15 for boys. More than one source of information was the most common ( $49 \%$ ) followed by mother only $(20 \%) .85 \%$ of parents reported talking to their teens about pubertal development and sexuality. There were several differences between areas reported covered by parents but not by teens, for example $72 \%$ of parents reported talking to their teens about gender differences in growth but only $31 \%$ of teens reported being spoken to about that. Areas that are very poorly covered are breast development in boys and sexual assault/date rape in girls at $5 \%$ and $26 \%$ respectively. In summary, it appears that we continue to do a relatively poor job in educating our kids about their development and sexuality and we do it late. Boys are even less likely than girls to be talked to about many areas of pubertal development and sexuality and when that is done, it is done at a later age.

Keywords: Puberty, adolescence, adolescent sexuality, sex education, United States

Correspondence: Hatim Omar, MD, Director, Adolescent Medicine, Dept. of Pediatrics, Room J422, KY Clinic, University of Kentucky Medical Center, Lexington, KY 40536-0284, United States. Tel: 859 323-5643, Fax: 859 257-7706. E-mail: haomar2@uky.edu

Submitted: September 01, 2002. Revised: September 28, 2002. Accepted: September 29, 2002.

\section{INTRODUCTION}

The medical literature is consistent on the importance of educating adolescents about sex and pubertal development (1-7). By the twelfth grade, greater than $60 \%$ of adolescents have had sex, with $45.6 \%$ of high school age students reporting having ever been sexually active (8). Nationally, $6.8 \%$ of teens report initiation of sexual intercourse prior to 13 years of age (8). Medical literature also supports the finding that we need to improve our com- munication to teens about puberty and sexuality $(6,9-11)$.

During puberty, adolescents undergo many physical and psychosocial changes in a relatively short period of time. They double their weight and gain approximately $25 \%$ in height, a growth spurt only exceeded in infancy (12). Most teens develop the ability for sequential logical thinking, the final adult stage of cognitive development, by age 16 years (13). They can reproduce and cause injury to self and others. They 
struggle to establish independence from their parents, to establish relationships with peers and significant others, to establish sexual identity, to finish school, and to prepare for a job or career. It is a time of intense idealism and extreme self-centeredness (12). It is a time when the peer group is valued over all others and a critical attitude is adopted towards established social norms. Being armed with appropriate information about expected changes in their body during puberty and about sexual topics could help to ease their transition through this period. In this study, we investigated the extent of pubertal development and sexuality education as seen by adolescents and parents.

\section{METHODS}

We conducted a survey of young college students (late adolescents) between the ages of 18 and 22 years. Students were asked to fill in a written questionnaire that asked about education regarding pubertal development and sexuality with help available for those who found any question unclear. Subjects were also asked about their demographic data, but they were kept anonymous to allow privacy. A total of 600 surveys were distributed equally between male (M) and female (F) subjects and $409(172 \mathrm{M}$ and $237 \mathrm{~F}$ ) were returned for a response rate of $68.2 \%$.

Median age for both $M$ and $F$ was 19 years. $65 \%$ of $M$ and $61 \%$ of $F$ respondents lived with both parents at the start of their pubertal development and the rest lived with a single parent. $30 \%$ of $\mathrm{M}$ and $24 \%$ of $F$ respondents had one or more older siblings. We also surveyed parents of adolescents who were patients in our clinic. A total of 200 surveys were distributed to parents and they were asked about their demographic data and then the same questions that the adolescents were asked. A total of 124 parents $(56 \% \mathrm{~F}$ and $44 \% \mathrm{M})$ completed the survey for a response rate of
$62 \%$. The median age for parents was 39 years. Percentages were calculated from both surveys in regards to most aspects of pubertal development and sexuality.

\section{RESULTS}

$85 \%$ of parents reported talking to their adolescents about puberty and sexuality and that the age at which that was done was a median of 13 years for $F$ and 15 years for M. In contrast, $83 \%$ of teens said that someone had spoken to them about these issues. Strikingly only $63 \%$ of males said they were educated on puberty and sexuality while $98 \%$ of females said they were. Adolescents agreed with parents that the median age at which they were educated on puberty was 15 years for boys and 13 years for girls. According to the adolescents the most common way of obtaining information on puberty/sexuality was from multiple sources $(49 \%)$ followed by mother $20 \%$ (see Table 1).

\section{Male adolescents}

A very poorly covered area in male adolescents was that of breast development (gynecomastia) where no parents reported mentioning that and only $5 \%$ of male adolescents said that someone had

Table 1. Who spoke to teen about puberty?

$\%$ Teens \% Males \% Females

\begin{tabular}{lccc}
\hline Father & 3 & 10 & 0 \\
Mother & 20 & 2 & 29 \\
Sibling & 9 & 14 & 7 \\
Teacher & 6 & 12 & 3 \\
Doctor & 2 & 1 & 3 \\
Friends & 5 & 10 & 3 \\
Other & 5 & 7 & 4 \\
More than & 49 & 43 & 51 \\
one & & \\
\hline
\end{tabular}


Table 2. The \% of parents reporting talking to their male adolescents about puberty and sexuality and \% of male adolescents who say they were educated on the same subject

\begin{tabular}{lcc}
\hline & $\begin{array}{c}\text { \% Parents reporting } \\
\text { talking to male teen }\end{array}$ & $\begin{array}{c}\text { \% Male teens reporting } \\
\text { being talked to by parent }\end{array}$ \\
\hline Breast Development & 0 & 5 \\
Testicular size/growth & 28 & 26 \\
Body odor & 69 & 38 \\
Pubic hair & 48 & 28 \\
Auxiliary hair & 46 & 15 \\
Acne & 74 & 15 \\
Increase in penis size & 24 & 9 \\
Spontaneous erection & 28 & 27 \\
Growth spurt & 65 & 31 \\
Gender difference in growth & 63 & 28 \\
Pregnancy protection & 22 & 20 \\
Sex in general & 59 & 48 \\
Wet dreams & 33 & 22 \\
STIs & 22 & 32 \\
Same sex attraction & 15 & 16 \\
HIV/AIDS & 70 & 58 \\
\hline
\end{tabular}

mentioned it to them (see Table 2). Many areas were also poorly covered such as penile growth, sexually transmitted infections (STI's), pregnancy protection and same sex attraction. In other areas such as body odor, gender differences and growth spurt, more parents said that they spoke to their adolescents about these subjects, while adolescents reported a much smaller percentage (see Table 2).

\section{Female adolescents}

Overall, there was more education provided to female adolescents than to their male counterparts and more agreement between what parents and adolescents reported (see Table 3). Same sex attraction and sexual abuse/date rape were among the least covered areas while breast development and menstrual periods were the most commonly covered (see Table 3 ).

\section{DISCUSSION}

This study addresses an area of adolescent development that has the potential of improving or worsening the future of our adolescents. Pubertal development and sexuality are major parts of adolescent development and main determinants of adulthood success. For example an early teen pregnancy or a major sexually transmitted disease can have a profound negative effect on early adulthood or the entire life span of a person. Many of the negative outcomes can be improved by providing timely and comprehensive education regarding puberty and sexuality.

There are however several limitations of this study. The subjective nature of the survey, the potential for misunderstanding of the questionnaire and the anonymity of the respondents impairs our ability to match parents and adolescents. Also the study was 
Table 3. The \% of parents reporting talking to their female adolescents about puberty and sexuality and \% of female adolescents who say they were educated on the same subject

$\%$ Parents reporting talking \% Female teens reporting being to female teen talked to by parent

\begin{tabular}{lcl}
\hline Breast Development & 91 & 85 \\
Menstrual Periods & 93 & 96 \\
Body odor & 83 & 43 \\
Pubic hair & 81 & 62 \\
Axillary hair & 78 & 29 \\
Acne & 86 & 65 \\
Growth spurt & 83 & 46 \\
Wet dreams & 14 & 14 \\
Gender difference in growth & 81 & 35 \\
Pregnancy protection & 59 & 58 \\
Sex in general & 67 & 50 \\
Rape/Sexual abuse & 29 & 26 \\
Vaginal discharge & 45 & 45 \\
STIs & 14 & 42 \\
Same sex attraction & 9 & 20 \\
HIV/AIDS & 70 & 75 \\
\hline
\end{tabular}

conducted in one state rather than on a national scale, which limits the potential for generalizing the results. That being said, the results are nevertheless useful in shedding some light on the extent of pubertal development/sexuality education our adolescents receive.

The results of this study showed significant deficiencies in the education our adolescents receive prior to and during puberty on several important issues. There is almost complete absence of education in regard to male gynecomastia despite the fact that more than $50 \%$ of males have it (14). This is important because many of these adolescents are confused and sometimes depressed by gynecomastia. We had several male adolescents that had to be treated for depression and two attempted suicide because of fear that they were "turning into girls" when they noticed they were developing breasts (unpublished observations).

Very little education seems to be provided in such areas as sexual abuse and date rape, gender differences in growth, pregnancy protection, same sex attraction and STI's (except for HIV, see Table 3). At a time when teen pregnancy, STI's and acquaintance rape are very common it is no wonder that many of our adolescents are not aware of these problems because of lack of or inadequate knowledge. Overall boys generally receive less attention than girls on all aspects of sexuality (Table 2, 3). Although physicians may be part of the "more than one" source of education, it is still surprising that only $2 \%$ of teens said that doctors were their source of information. Pediatricians should be in the 
forefront of providing accurate and timely education to their patients during routine visits.

\section{CONCLUSION}

Based on this study, we conclude that a relatively small proportion of our adolescents are armed with adequate information about most areas of pubertal development and sexual issues. Furthermore, the age at which most adolescents receive such information, if addressed at all, is past the age of onset of puberty for many teens. More thorough and timely education on pubertal development is needed to allow our teens to make wellinformed choices in regards to their sexual life and to help prevent many problems related to poor choices resulting from inadequate and late sexuality educations.

\section{REFERENCES}

1. American Academy of Pediatrics. Committee on school health. School health assessments. Pediatrics 2000; 105(4):875-7.

2. Kirby D. Sexuality and sex education at home and school. Adolesc Med 1999;10(2):195-209.

3. DiCenso A. Interventions to reduce unintended pregnancies among adolescents: A systematic review of randomized controlled trials. BMJ 2002;324:1426.

4. Ogden J. The timing, format and content of school based sex education: An experience with a lasting effect? Br J Fam Plann 1999;35(3)115-8.

5. Jemmott JB, Sweet Jemmott L, Fong GT. Abstinence and safer sex HIV risk-reduction interventions for African American adolescents: A randomized controlled trial. JAMA 1998;279(19):1529-36.

6. DiCenso A. Completing the picture: adolescents talk about what's missing in sexual health services. Can J Public Health. 2001; 92(1):35-8.

7. Blake SM. Effects of a parent-child communications intervention on young adolescents' risk for early onset of sexual intercourse. Fam Plan Perspect 2001;33(2):52-61.

8. Centers for Disease Control. Youth risk behavior surveillance-United States, 2001. MMWR 51:(No. SS-4), 2002.

9. Jordan TR, Price JH, Fitzgerald S. Rural parents' communication with their teen-agers about sexual issues. J Sch Health 2000;70(8): 338-44.

10. Measor L, Tiffin C, Miller K. Health professionals and the sex education of adolescents. Nurs Times 1999;95(21): 48-51.

11. Romero-de-Castilla-Gil RJ, LoraLerenzo MN, Canete-Estrada $R$. Adolescents and sources of sex information: preferences and perceived usefulness. Aten Primaria. 2001;27(1):12-7.

12. Strasburger V. Getting teenagers to say no to sex, drugs, and violence in the new millennium. Med Clin North Am 2000;84(4):787-810.

13. Piaget J. Intellectual evolution from adolescence to adulthood. Hum Dev 1972;15:1.

14. Biro FM, Lucky AW, Huster GA, Morrison GA: Hormonal studies and physical maturation in adolescent gynecomastia. J Pediatr 1990;116: 450-5. 